\title{
Human Skeletal Remains from the Tyson Site (41SY92)
}

Helen D. Dockall

Unknown

Follow this and additional works at: https://scholarworks.sfasu.edu/ita

Part of the American Material Culture Commons, Archaeological Anthropology Commons, Environmental Studies Commons, Other American Studies Commons, Other Arts and Humanities Commons, Other History of Art, Architecture, and Archaeology Commons, and the United States History Commons

Tell us how this article helped you.

This Article is brought to you for free and open access by the Center for Regional Heritage Research at SFA ScholarWorks. It has been accepted for inclusion in Index of Texas Archaeology: Open Access Gray Literature from the Lone Star State by an authorized editor of SFA ScholarWorks. For more information, please contact cdsscholarworks@sfasu.edu. 


\section{Human Skeletal Remains from the Tyson Site (41SY92) \\ Creative Commons License \\ (c) $($ ) $(9)$}

This work is licensed under a Creative Commons Attribution-NonCommercial 4.0 International License 


\title{
HUMAN SKELETAL REMAINS FROM THE \\ TYSON SITE (41SY92)
}

by

\author{
Helen Danzeiser Dockall
}

\section{INTRODUCTION}

During the 1993 field season at the Tyson site (41SY92), conducted by the East Texas and Northeast Texas Archaeological societies, two burial features were uncovered (Features 14 and 15). These features contained the skeletal remains of three Caddo subadults, ranging in age from birth to one to two years. Burial 1 (Feature 14) yielded the partial skeleton of a child less than two years old, as well as elements of a second, slightly younger, child. Burial 2 (Feature 15) produced the remains of a well-preserved infant. This article describes the excavation and osteology protocols, a description of taphonomic conditions, inventory of these burials, demography, size of the subadults, their state of health, and cranial modification.

\section{EXCAVATION PROTOCOL}

When the burials were located in the field, the skeletal remains were cleared enough to determine their extent; these elements were mapped, as were associated grave goods. At that time, the grave goods were removed for cataloging and processing and the decision was made to remove the burials in matrix. Two blocks of soil, one for each feature, were removed from the ground. In order to stabilize the burials, a spray foam sealant was applied. The burials were then transported to the Physical Anthropology Laboratory of Texas A\&M University for excavation and analysis.

Excavation procedure consisted of carefully removing the sealant covering the burials and then excavating the skeletal remains from the matrix. The burials were excavated using bamboo tools, small wooden dowels, and paint brushes. During the 
excavation, black and white photographs were taken using Plus X Pan film, and color slides were taken using Kodachrome. Once the remains were exposed, maps were drawn showing the relationship of skeletal elements to each other and to associated grave goods (see below). All soil was screened through 1/8-inch screen to recover small skeletal elements and artifacts (such as shell beads). Soil samples were taken from the lower leg regions of both burial features.

\section{OSTEOLOGY PROTOCOL}

Determining sex for subadults, even those as complete as Burial 2, is difficult, primarily because the techniques employed by bioarchaeologists for determining sex are based on secondary sexual characteristics, or those which develop after puberty (Bass 1987; Hunt and Gleiser 1955). Because of this, no method of sexing subadult remains has been accepted as a standard. The subadults described in this analysis were not assessed as to their sex.

Aging criteria were based on the state of bone and dental development following criteria described in Steele and Bramblett (1988) and Ubelaker (1978). Length of postcranial elements was also used to assess age following Fazekas and Kosa (1978) and Marek (1990). All measurements were taken three times and then averaged to insure accuracy of the dimensions. According to Steele and Bramblett (1988:6), the term infant is used to describe a child ranging from birth through two years of age. However, for the purposes of this article, the term infant is confined to a child less than a year old, while the term child is reserved for individuals over a year old.

After determining age, the skeletons were examined for dental, cranial, and postcranial disorders. Areas suggestive of a disorder were assessed using a 10X hand lens and a dissecting microscope. 


\section{TAPHONOMY}

Taphonomy describes postmortem changes in the condition of bone as it degrades and decomposes (Haglund 1991:1). Although the two burial features at the Tyson site were located in close proximity, the taphonomic condition of the bone differed markedly. The subadult from Feature 15 was remarkably well-preserved, especially given the extremely young age of the infant and the fact that infants often preserve very poorly. Almost all bones were intact and still in articulation with each other. Very little in the way of destructive taphonomic changes had occurred.

The skeletal remains from Feature 14, on the other hand, had undergone great taphonomic changes and were not in a good state of preservation. Faunalturbation was unequivocally evident in the filled tracks left by a burrowing animal, clearly seen throughout the chest region. All the ribs and vertebrae had been driven to the left upper area of the thorax during the burrowing process. There were also worm holes full of processed dirt throughout the burial feature. Rodent gnawing was apparent on the left femur and a "window" had been created on the dorsal surface where the cortex had been completly gnawed away. The burial was badly disarticulated with the left tibia directly beneath the right one. In addition, the os coxae were not recovered, nor were many arm bones. The skull had been severely fragmented under the weight of a ceramic vessel. The impression of the base of the vessel was still clearly visible in the matrix when the burial was excavated. Root damage was essentially absent on the remains of Feature 14, as they were for Feature 15.

\section{BURIAL INVENTORY}

Burial 1: Burial 1 consisted of the remains of two individuals (Table 1). The first individual (B. 1a) was represented by dental, cranial, and postcranial remains. The only portions of the face recovered include the fragmented maxillae and mandible, in addition 
TABLE 1: INVENTORY OF SKELETAL REMAINS FROM BURIALS 1 AND 2

\begin{tabular}{|c|c|c|c|c|c|}
\hline \multirow[t]{2}{*}{ ELEMENT } & \multicolumn{2}{|r|}{ BURIAL 1} & \multirow[b]{2}{*}{ Left } & \multicolumn{2}{|c|}{ BURIAL 2} \\
\hline & Left & $U^{1} \quad$ Right & & & \\
\hline \multicolumn{6}{|l|}{ Cranlal } \\
\hline Zygomatic & - & - & C & & C \\
\hline Maxilla & P.F & P.F & P.F & & $\mathrm{P}$ \\
\hline Mandible & & $P$ & - & & P.F \\
\hline Sphenold & & $\mathrm{P}$ & & P.F & \\
\hline Frontal & P.F & P.F & C & & C \\
\hline Pardetal & $C, F$ & C,F & C.F & & C.F \\
\hline Temporal & $\mathrm{P} ; \mathrm{P}$ & $P ; P$ & P.F & & $P$ \\
\hline Occipital & & $P, F$ & & P & \\
\hline Incus & - & - & - & & C \\
\hline \multicolumn{6}{|l|}{ Postcranlal } \\
\hline Clavicle & $\mathrm{L}$ & - & - & & - \\
\hline Scapula & P & $\mathrm{P}$ & P & & $\mathrm{P}$ \\
\hline Humerus & - & D & - & & $\mathrm{C}$ \\
\hline Radius & - & C & $C, F$ & & C.F \\
\hline Ulna & - & - & $C, F$ & & C.F \\
\hline Metacarpals & - & - & & $2 \mathrm{C}$ & \\
\hline Carpals & - & - & & $1 \mathrm{C}$ & \\
\hline Hand Phal. & & $1 \mathrm{C}$ & & - & \\
\hline Vertebrae $^{2}$ & & $5 C, 5 F$ & & $22 \mathrm{C}$ & \\
\hline Ribs & $\mathrm{F}$ & $\mathrm{F}$ & $\mathrm{F}$ & & F \\
\hline Illum & - & - & $\mathrm{C}$ & & $\mathrm{C}$ \\
\hline Ischlum & - & - & $\mathrm{C}$ & & $\mathrm{C}$ \\
\hline Pubis & - & - & C & & C \\
\hline Femur & WE & WE & $\mathrm{C}, \mathrm{F}$ & & $\mathrm{C}, \mathrm{F}$ \\
\hline Tybla & $\mathrm{P}$ & WE & - & & C \\
\hline Fibula & - & - & D & & $\mathrm{C}, \mathrm{F}$ \\
\hline Metatarsal & - & - & & $2 \mathrm{C}$ & \\
\hline Foot phal. & - & - & $3 C$ & & \\
\hline
\end{tabular}

KEY:

$$
\begin{array}{ll}
\mathrm{C}=\text { complete } & \mathrm{P}=\text { partial } \\
\mathrm{Pr}=\text { proximal } & \mathrm{D}=\text { distal } \\
\mathrm{F}=\text { fragmentery } & \mathrm{WE}=\text { whole, with eroded ends }
\end{array}
$$

${ }^{1}$ This column represents those elements that are unpaired and those for which the side is indeterminate.

${ }^{2}$ The vertebrae count is based soiely on vertebral centra, not arches. 
TABLE 2: INVENTORY OF TEETH FROM BURIALS 1 AND 2

BURIAT 1

Mandible

\begin{tabular}{lll}
\hline & Left & Right \\
dil & 1 & 1 \\
di2 & 1 & 0 \\
dc & 0 & 0 \\
dp3 & 1 & 0 \\
dp4 & 0 & 0
\end{tabular}

KEY:
BURIAT 2

Madila Mandible

Right

Left Right

Right

Left

0

0

0

0

$\begin{array}{ll}0 & 0 \\ 0 & 0\end{array}$

0

0

0

0

0
0
0
0

0

0

0

0

0
0
0
1
0

$0=$ not present, $1=$ present 
to six deciduous teeth (Table 2). The calvarium consisted of fragmented frontals, temporals, parietals, and occipital. Postcranial recovery was limited to portions of the left shoulder girdle, trunk, and right arm. The lower body was represented solely by both femora and tibiae.

The second individual in this feature (B. 1b) was represented only by both temporals and a portion of the left scapula, all of which were also recovered with the first skeleton. Because these elements were recovered from the far left hand side of the excavated pedestal, it is the author's contention that the bones representing the rest of this child may be immediately adjacent to the excavated unit. Those elements recovered with Burial 1a are thought to be the result of faunalturbation disturbing the remains of $\mathrm{B} .1 \mathrm{~b}$ and commingling them with B. 1a.

Eight ceramic vessels, shells, and an antler rack had been placed on this burial and were excavated in the field (see Middlebrook, this volume). In addition to these grave goods, shell artifacts and red ocher were encountered during the lab excavation. A total of seven columella beads were found in the grave fill, primarily around the neck region of Burial 1a. Four rectangular pieces of worked shell were also found in the fill. The lack of holes indicate that they did not function as pendants, and their use is unknown. Red ocher was encountered throughout the grave fill, but it does not appear worked, and may be a naturally occurring element in the soil.

Burial 2: This burial represents the remains of one infant. The body was quite complete (see Table 1). Facial elements include both zygomatics, maxillae, a hemimandible, and one deciduous molar (see Table 2). Complete frontals and fragmented temporals and parietals remained, as did a portion of the sphenoid and a complete bone of the inner ear. Elements of both shoulder girdles, both arms, and hands were recovered. Almost all vertebrae and ribs were recovered in situ as was the pelvic girdle. Both legs and elements of the feet were also found. Red ocher was also found with this burial, but like Burial 1, it 
was not worked and may have been a natural occurrence. A freshwater mussel shell was placed below the baby's chin. From the shell's position and placement, it seems to have been put there intentionally.

\section{DEMOGRAPHY}

The individual represented by the majority of skeletal remains in Burial 1 (B. 1a) is believed to be one to two years old, with the most likely estimate being one and a half years. This assessment is based on bone ossification, dental development, and the length of the femora (Table 3). Occipital fusion usually begins by the fourth year of life; this

TABLE 3: MEASUREMENTS (in mm) OF BURIALS 1 AND $2^{1}$

ELEMENT

\begin{tabular}{|c|c|c|c|c|c|c|}
\hline & Left & $\mathbf{U}$ & Right & Left & $\mathbf{U}$ & Right \\
\hline Occipital $^{2}$ & - & & - & 24 & & 23 \\
\hline Humerus & - & & - & - & & 65 \\
\hline Ulna & - & & - & 62 & & - \\
\hline Ilium- Max. Ing. & - & & - & 34 & & 35 \\
\hline Ilium- Max. wdt. & - & & - & 32 & & 31 \\
\hline Ischlum & - & & - & 17 & & 17 \\
\hline Pubis & - & & - & 17 & & 18 \\
\hline Femur & 121 & & 120 & 78 & & - \\
\hline Tibia & - & & - & - & & 68 \\
\hline
\end{tabular}

${ }^{1}$ All measurements are for length unless otherwise noted.

${ }^{2}$ Lateral condylar portions of the occipital 
individual still has separate elements. In addition, the metopic suture of the frontal bone is still open, indicating an age of less than two years. All teeth recovered from this individual are deciduous, and their state of development indicates an age of 1 year \pm four months. The length of the femora most closely approximates an 18 month old child (Marek 1990:64); however, a comparison to Ubelaker's (1978:48-49) data puts the femoral length in an age range from six months to 18 months. The measurements from Burial 1 place it at the upper end of this range. All of these age indicators support an age between one and two years, with the best support for the age close to 18 months.

The second individual in Burial 1 (B. 1b), represented only by both petrosals of the temporals and the glenoid and acromion portions of the left scapula, is a child but an exact age assessment is impossible. However, based on size alone, this child seems to be of the same age, or a few months younger, than the more complete burial in this feature.

The individual representing Burial 2 is a newborn infant, as determined by bone size and bone and dental development. The occipital is still unfused and the frontal bones have not yet joined. In addition, the mandible still consists of two unfused hemimandibles, which usually fuse by the end of the first year. The crown for a deciduous first upper premolar is present; its stage of development suggests an age of birth \pm two months. This assessment is supported by measurements taken on the long bones (see Table 3), which suggest an age of 10 fetal months (Fazekas and Kósa 1978). Measurements of both lateral portions of the occipital support this age as well.

\section{SIZE}

Measurements used to assess size are presented in Table 3. In young children such as these, size is of more critical importance in determining age than biological affinity. They cannot be used, however, to assess the degree of sexual dimorphism because sex is not known. Therefore, the measures are presented here strictly as evidence of the age suggested by the bioarchaeologist for the burials, and for comparative purposes for other 
researchers. Over a hundred measurements can potentially be evaluated on a complete fetal skeleton (see Fazekas and Kósa 1978); the fragmentary nature of the individuals recovered from the Tyson site limited the selected measurements. I further limited the measured dimensions to those that are frequently cited in comparative reports, such as length.

\section{HEALTH}

Although cranial and postcranial remains were examined for signs of medical disorders, none were identified on these burials. In interpreting this finding, it must be considered that the extreme fragmentation of the primary individual in Burial 1 may have obscured existing medical disorderd, and the paucity of skeletal remains associated with the secondary individual (B. 1b) precludes thorough examination. However, fragmentation and a lack of skeletal remains are not issues with Burial 2. Presumably, if lesions had been present on the bones of this individual, they would have been located and identified. Because of the lack of skeletal indicators of health, no specific reasons for the cause of death of any of these individuals could be identified. Apparently, their cause for death was either such that no traces were ever left on bone, or they died before their bone could be impacted.

\section{CRANIAL MODIFICATION}

The primary individual in Burial 1 exhibits a possible case of artificial cranial modification. The right and left frontal bones of the child show A transverse depression near the coronal suture. A raised area of bone lies immediately behind this depression, but directly in front of the suture. This produces a coronal ridge which is characteristic of some forms of cranial modification (Loveland 1980:118). Loveland (1980:118) noted that this depression and subsequent ridge is "probably produced by means of an elongated bag of sand (or clay) being strapped transversely across the skull near the coronal suture and 
held in place by the board on top." An ethnohistoric account of one Coushatta group living along the Trinity River approximately $25 \mathrm{~km}$ from Galveston Bay described the technique for modifying the skulls of children. When the child was a week and a half old it was:

...strapped on a board, as a cradle. A small concavity at one end of the board served to hold a lump of wet clay in which the infant's head was imbedded; (the infant lying on its back). Another lump of clay was strapped on tightly bandaged over the infant's forehead, that bandage being gradually tightened as the soft skull yielded to the pressure (Dyer 1916:3).

The impression left on the frontal bones of this Caddoan child corresponds well with what one would expect to see given the above descriptions. However, due to the fragmented nature of the frontal bones, the identification of cranial modification should be viewed as equivocal.

\section{DISCUSSION}

Literature pertaining to the analysis of Caddoan human skeletal remains was reviewed to find subadults of a comparable age to those at the Tyson site for comparison in terms of disorders and cranial modifications. Seven sites had comparable data, including Cedar Grove (Rose 1984), Horton (Brues 1958), Morris (Brues 1959), Nagle (Brues 1957), Roden (Rose et al. 1981), Smullins (Elkins 1959), and Spike (Derrick and Steele 1993). Of these sites, only Spike is located in Texas; the rest of the comparative data come from Oklahoma (Horton, Morris, Nagle, Roden, and Smullins) and Arkansas (Cedar Grove). However, some caveats must be given in using this comparative data. First, many reports did not define the terms newborn and infant. For instance, Elkins (1959) used the term infant for children ranging in age from one to three years old. It is unclear how this term was used in other studies, as it is unclear as to how researchers were defining a newborn. For these reasons, instead of focusing on subadults 
corresponding tightly in age to those in this study, any child under the age of two years was included in the comparative data. Second, there is no way to control for the degree of fragmentation of individuals within these sites. Clearly, the more fragmented a sample, the less it is to provide evidence of health disorders or cranial modifications.

Given these caveats, the seven sites produced a total of 28 children under the age of two years to compare with the three from the Tyson site. Fourteen of the individuals were children aged one year or older, and 14 were less than a year old. Of the infants, 10 were six months old or less, one was nine months old, and three were given the generalized term "infant" in the original reports, with no more accurate age assessment possible. When examining the comparative sample for health disorders, 35.7 percent of the infants and children exhibited evidence of health problems. Of these, all showed signs of periostitis, while one ( 3.6 percent) had porotic hyperostosis and cribra orbitalia, in addition to periostitis. Sixty percent of the infants had medical disorders, while only 40 percent of the older children did.

The only other comparative data came from a survey done by Burnett (1990) of human skeletal remains from the eastern portion of the Gulf Coastal Plain in Texas. Her synthesis of skeletal data from the Middle Sabine drainage is based on three prehistoric samples and one historic sample totaling 38 individuals. Comparisons here are limited to the 30 prehistoric individuals who can be assigned to the Early, Middle, or Late Caddo periods (Burnett 1990:406). Of these, only two individuals were subadults, and neither had signs of infections. Burnett (1990:407) noted that Late Caddo samples from the Middle Sabine region, and ones in the Sulphur, Cypress, and Upper Sabine regions, all had low rates of adult and subadult infection. She further noted that:

all of these sites...are either small or have sparse occupational debris. It appears that higher infection rates are restricted to the large mound centers located along the Red River and the prehistoric Cooper Lake inhabitants 
who resided in an area thought to be marginal to the Caddoan culture area (Burnett 1990:407).

None of the reports mentioned cranial modifications to the subadults. Signs of modification would not be expected in the skeletal remains of newborns, but it is possible for even young children to show signs of this alteration. It is impossible to know whether the lack of modification in the comparative samples is the result of fragmentation and poor preservation, or whether these children, for cultural reasons, did not undergo cranial modification.

\section{CONCLUSIONS}

A bioarchaeological analysis of the human skeletal remains excavated from the Tyson site (41SY92) established that the remains from Features 14 and 15 represented a total of three individuals, rather than the two that were expected based on field assessments. Feature 14 contained the remains of a child between the ages of one and two years old (B. 1a), although the most likely age estimate is 18 months. The frontal bones of this child show evidence of possible cranial modification in the form of a transverse depression, followed by a rise of bone near the coronal suture. In addition to this individual, a second, probably younger child (B. 1b) was represented in Feature 14 by two petrosals of the temporal and a portion of a left scapula. It is likely that this child was buried next to the first one and elements were displaced by burrowing animals. Feature 15 (Burial 2) yielded the fairly complete osseous remains of an infant. Based on bone and dental development, as well as a metric evaluation, it was determined that this child is a neonate and was either stillborn, or died within a few days of its birth. None of the individuals from the Tyson site showed indications of disease, although the rate noted in the comparative samples was relatively high. 


\section{REFERENCES CITED}

Bass, W. M.

1987 Human Osteology: A Laboratory and Field Manual. Third Edition. Missouri Archaeological Society, Columbia, Missouri.

Brues, A. M.

1957 Skeletal Material from the Nagle Site. Bulletin of the Oklahoma Anthropological Society 5:101-106.

1958 Skeletal Material from the Horton Site. Bulletin of the Oklahoma Anthropological Society 6:27-32.

1959 Skeletal Material from the Morris Site. Bulletin of the Oklahoma Anthropological Society 7:63-70.

Burnett, B. A.

1990 The Bioarcheological Synthesis of the Eastern Portion of the Gulf Coastal Plain. In The Archeology and Bioarcheology of the Gulf Coastal Plain, by D. A. Story, J. A. Guy, B. A. Burnett, M. D. Freeman, J. C. Rose, D. G. Steele, B. W. Olive, and K. J. Reinhard, pp. 385-418. Research Series No. 38. Arkansas Archeological Survey, Fayetteville.

Derrick, S. M. and D. G. Steele

1993 Analysis of Human Remains from 41DT6 and 41DT16. In Excavations at the Tick, Spike, Johns Creek, and Peerless Bottoms Sites, Cooper Lake Project, Delta and Hopkins Counties, Texas, by R. C. Fields, E. F. Gadus, L. W. Klement, C. B. Bousman, and J. B. McLerran, pp. 271-286. Report of Investigations No. 91. Prewitt and Associates, Inc., Austin.

Dyer, J. O.

1916 Comparisons of Wild Tribes Near Galveston a Century Ago with Ancient Semitic Customs. Center for American History at the University of Texas at Austin.

Elkins, A.

1959 The Skeletal Material from Ck-44, the Smullins Site. Bulletin of the Oklahoma Anthropological Society 7:55-61.

Fazekas, I. G. and F. Kósa

1978 Forensic Fetal Osteology. Akadémiai Kiado, Budapest, Hungary.

Haglund, W. D.

1991 Applications of Taphonomic Models to Forensic Investigations. Ph.D. dissertation, University of Washington, Seattle.

Hunt, E. E. and I. Gleiser

1955 The Estimation of Age and Sex of Preadolescent Children from Bone and Teeth. American Journal of Physical Anthropology 7:207-255.

Loveland, C. J.

1980 The Skeletal Biology of the Caddo Indians of the Kaufman-Williams Site, Red River County, Texas. Ph.D. dissertation, University of Tennessee, Knoxville. 
Marek, M.

1990 Long Bone Growth of Mimbres Subadults from the NAN Ranch (LA15049), New Mexico. Master's thesis, Texas A\&M University, College Station.

Rose, J. C.

1984 Bioarcheology of the Cedar Grove Site. In Cedar Grove: An Interdisciplinary Investigation of a Late Caddo Farmstead in the Red River Valley, edited by N. L. Trubowitz, pp. 227-256. Research Series No. 23. Arkansas Archeological Survey, Fayetteville.

Rose, J. C., P. M. Clancy, and P. H. Moore-Jansen

1981 Bioarchaeology of the Roden Site. In Archaeological Investigations at the Roden Site (MC-215), McCurtain County, Oklahoma, by G. Perino, pp. 99-129. Potsherd Press, Publication No. 1. Museum of the Red River, Idabel, Oklahoma.

Steele, D. G. and C. A. Bramblett

1988 The Anatomy and Biology of the Human Skeleton. Texas A\&M University Press, College Station.

Ubelaker, D. H.

1978 Human Skeletal Remains: Excavation, Analysis, Interpretation. Taraxacum, Washington, D.C. 